\title{
RESTORATION OF MEMORY AND ACETYLCHOLINESTERASE ACTIVITY BY MICHELIA CHAMPACA IN CHRONICALLY NOISE-STRESSED WISTAR ALBINO RATS
}

\author{
MALATHI S, VIDYASHREE HM, RAVINDRAN RAJAN* \\ Department of Physiology, Dr. ALM PG Institute of Basic Medical Sciences, University of Madras, Chennai, Tamil Nadu, India. \\ Email: dr.ravindranrajan87@gmail.com
}

Received: 18 July 2016, Revised and Accepted: 25 August 2016

\section{ABSTRACT}

Objective: The ability of an organism to adapt to aversive stressful situations or life challenging circumstances is very crucial to its state of health and survival. However, the breakdown in adaptation due to persistent uncontrollable stress leads to impairment of bodily functions and the onset of a variety of pathological disorders, especially memory decline. This study was designed to evaluate the effect of Michelia champaca a potent antioxidant on chronic noise-stress-induced memory impairment in rats.

Methods: Male Wistar albino rats were used in this study. Animals were exposed to noise for 30 consecutive days (4 hrs/day) before testing for memory. Thereafter, the plasma corticosterone level and acetylcholinesterase (AchE) activity were estimated in the three discrete regions of the brain homogenate using a spectrophotometer.

Result: Our results showed that $M$. champaca prevented memory impairment and suppressed corticosterone concentrations induced by chronic noise stress. Moreover, it also decreased brain AchE activity when compared with the chronic stress group $(\mathrm{p}<0.05)$.

Conclusions: These findings suggest that M. champaca attenuates memory deficits induced by chronic noise stress in albino rats and may be useful therapeutically for stress-related cognitive dysfunctions. The reduction in the levels of serum corticosterone and inhibition of cholinesterase enzyme might be contributing significantly to the positive effect of $M$. champaca on memory in rats exposed to chronic noise stress.

Keywords: Michelia champaca, Memory, Corticosterone, Chronic noise stress, Acetylcholinesterase activity, Eight-arm radial maze.

(C) 2016 The Authors. Published by Innovare Academic Sciences Pvt Ltd. This is an open access article under the CC BY license (http://creativecommons. org/licenses/by/4. 0/) DOI: http://dx.doi.org/10.22159/ajpcr.2016.v9i6.14177

\section{INTRODUCTION}

Severe stressful conditions are responsible for the etiopathogenesis of various psychosomatic disorders. Homeostasis is controlled by various physiological mediators working in concert by interacting with receptors placed at various physiological levels, and the functional identity of neurotransmitters is challenged during stressful conditions [1]. Many processes intervene between stressful stimulus and subsequent responses in the body. A variety of neurochemical reactions are also involved during these processes both in central and autonomic nervous system. Acetylcholinesterase (AchE) is an important cholinergic enzyme that plays a key role during these processes [2]. Extensive studies have been reported on the changes in the adrenergic system in the brain after exposure to stress. Recent investigations indicate that stress conditions could modulate the central cholinergic system in animals [3], which plays an important role in learning and memory processes. Dementia is largely a hidden problem as per the epidemiological studies in India. Prevalence rates for dementia increase exponentially with advancing age. Since allopathic system of medicine has been yet to provide a radical cure, it is worthwhile to look into new directions, which would minimize the incidents of memory loss [4]. Moreover, there are few reports available to show the changes in the activity of AchE and corticosterone in discrete regions of the brain in animals induced by the various duration of stress and their effect on memory. Furthermore, the reports regarding the effects of Michelia champaca on noise stress on neurological system are very scanty. Noise in public places, especially in occupational environments is considered as a health hazard. The problem is more pertinent, particularly in occupational settings where exposure to noise for short periods is unavoidable. Plants have been a valuable source of natural products for maintaining human health for many years. More recently, there has been a greater search for natural therapies. M. champaca is a folk-medicinal plant, well known for its antioxidant and antidiabetic property, [5] it also has other numerous properties such as analgesic, anti-inflammatory, and [6] anticancer activities [5]. These unique effects may be due to the presence of phytochemicals, such as phenols, saponins, tannins, amino acids, flavonoids, terpenoids, and catecholamines, [7] involved in biological manipulations and activities. However, the perusal of literature reveals that, so far, no attempt was made to study the role of $M$. champaca in relation to chronic noise and central cholinergic system in the whole brain or in discrete areas of the brain in animal models has not been studied much. Hence, in this study, an attempt was made to elucidate the effect of chronic noise stress on the activity of AchE, corticosterone, and role of champaca in memory on chronically stressed male Wistar albino rats.

\section{METHODS}

The experiments were carried out using healthy adult male Wistar rats (180-200 g). The study was initiated with a proper approval by the Institute's Animal Ethical Committee (IAEC No.: 01/23/2015). Animals were divided into four groups (control, control treated with M. champaca, chronic noise exposed, and chronic noise-stressed rats treated with $M$. champaca. All the rats used in this study were maintained at a constant temperature with a $12 \mathrm{hrs}$ light: $12 \mathrm{hrs}$ dark cycle and allowed free access to food and water. All groups were handled similarly.

\section{Noise stress procedure}

Broadband (white) noise was produced by a white noise generator (0-26 KHZ) and amplified by an amplifier ( $40 \mathrm{~W})$ connected to two loudspeakers $(15 \mathrm{~W})$ located at $30 \mathrm{~cm}$ above the animal cage. The intensity of the sound was measured by a sound level meter (Quest electronics cygnet systems D2023, serial No F02199, India) and maintained at $100 \mathrm{dBA}$ intensity. Animals were exposed to noise 4 hrs daily for 30 days. To avoid the influence of handling stress, control rats were kept under the same set up during the corresponding period without exposing them to noise [8]. 
Preparation of methanol extract of $M$. champaca: Preparation of M. champaca plant extract

M. champaca was collected from the local area and confirmed by the botanist, and a sample was deposited in an herbarium (Reg. No.: NIS/ MB/94/2013). M. champaca dry flowers of 10 grams were soaked in $100 \mathrm{ml}$ (twice, i.e., $2 \times 100 \mathrm{ml}$ ) of methanol for 8-10 days at room temperature in dark conditions, stirring every $18 \mathrm{hrs}$ using sterile rod. The final extracts were filtered using a Whatman No 1 filter paper. The filtrate was concentrated to dryness under reduced pressure at $40^{\circ} \mathrm{C}$ using a rotary evaporator and stored at $4^{\circ} \mathrm{C}$ for further use. An oral dose of $400 \mathrm{mg} / \mathrm{kg} /$ body weight was administered orally in this study.

\section{Assay of corticosterone}

The corticosterone assay [8] is based on the oxidation of corticosteroids with ferric iron (III) in an acidic medium and subsequent complex with ferrous iron (II) and potassium hexacyanoferrate. $0.5 \mu$ l was mixed with appropriate volumes of the working solutions of corticosterone and were transferred into a series of $10 \mathrm{ml}$ volumetric flasks. $2 \mathrm{ml}$ of sulfuric acid and $2 \mathrm{ml}$ of ferric chloride were added to $0.5 \mathrm{ml}$ of potassium hexacyanoferrate (III) solution. This mixture was heated in a water bath maintained at $70^{\circ} \mathrm{C} \pm 2^{\circ} \mathrm{C}$ for 30 minutes with occasional shaking and diluted to the $5 \mathrm{ml}$ mark with distilled water. The absorbance was measured at $780 \mathrm{~nm}$ against the reagent blank.

\section{Assay of AchE}

The tissue was homogenized [9] (approximately $20 \mathrm{mg}$ of tissue per $\mathrm{ml}$ of phosphate buffer (PH8.0: $0.1 \mathrm{M}$ ) in a Potter-Elvehjem homogenizer. A $0.4 \mathrm{ml}$ aliquot of brain homogenate was added to a cuvette containing $2.6 \mathrm{ml}$ of phosphate buffer (pH8.0: $0.1 \mathrm{M}$ ) $100 \mu \mathrm{l}$ of 5,5-dithios-(2-nitrobenzoic acid) reagent was added to the photocell. The absorbance was measured at $412 \mathrm{~nm}$. Then, $0.02 \mathrm{ml}$ of acetylthiocholine iodide was added. Changes in the absorbance were recorded and the change in absorbance per minute was calculated, and 0.1 of esterine sulfate was added to the reaction mixture to determine the nonspecific esterase activity. The difference in the rate of activity was found, and the AChE activity was calculated. The enzyme activity was expressed as $\mu$ moles of AThI hydrolyzed/minutes/g tissue.

\section{Eight-arm radial maze (EAM)}

EAM is used to assess spatial learning and memory [10]. A group of animals was trained before the experiment and during training, food act as the reward to animals, and placed in their respective arms. Initially, animals were allowed to freely explore the maze with all arms baited with cereal. The adaptation occurs after a week; each rat was individually housed in a small cage. The adaptation and maze test were performed between 10 and $12 \mathrm{hrs}$. On the $3^{\text {rd }}$ day, for each rat, a piece of cereal in only four of the eight-arms was kept and was trained to locate the four food rewards. Each rat had its own set of four rewarded arms. The room contained several visual reference cues on the wall and only four arms (fixed for each animal). Each trial began with the placement of the animal on the central platform facing toward arm number one and ended when the rat had visited the four baited arms and the time taken was noted. Otherwise, the rats were given a maximum of after a period of 10 minutes. Reference and working memory error and time taken to complete the task were analyzed in all the groups.

\section{Statistical analysis}

Data were expressed as mean \pm standard deviation (SD). All the data were analyzed with the SPSS for windows statistical package (version 20.0, SPSS Institute Inc., Cary, North Carolina). The statistical significance among the four different groups was analyzed using one-way ANOVA test followed by Tukey's multiple comparison tests, and the significance level was fixed at $\mathrm{p}<0.05$.

\section{RESULTS}

Effect of chronic noise stress on corticosterone levels

The data were summarized in Fig. 1 with mean \pm SD. The plasma corticosterone level was measured in all the different groups. There were significant changes observed in the corticosterone level when compared between control, chronic noise-stress-exposed rats showed a significant increase in the corticosterone level compared to the rest of the groups control treated with $M$. champaca and noise-exposed rats which received $M$. champaca showed a significant decrease $(\mathrm{p}<0.05)$ when compared to stress groups. This indicates noise exposure acts as a stressor and M. champaca extract was found to be beneficial.

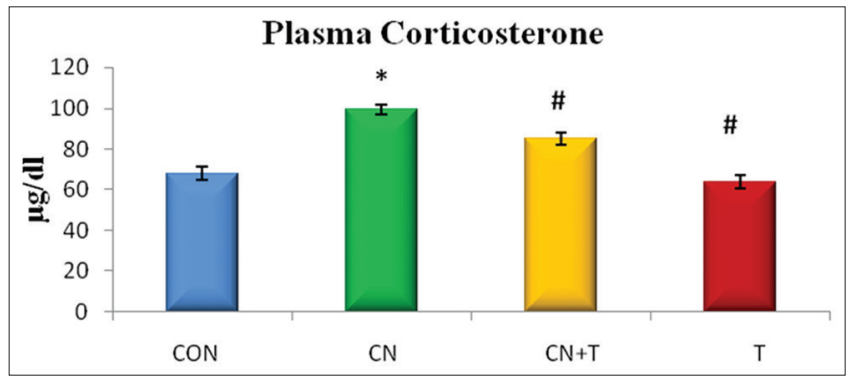

Fig. 1: Effect of Michelia champaca on plasma corticosterone in chronic noise-stress-induced rats. Values are expressed as mean \pm standard deviation, $n=6$. The symbols represent statistical significance: ${ }^{*, \#}<$ p 0.05 . ${ }^{*}$ Compared with saline control. \#Compared with chronic noise stress

Effect of chronic noise stress on AchE activity in discrete regions of brain

The data from various groups are presented as bar diagram with mean \pm SD (Figs. 2-4). The acetylcholine esterase activity in chronic noise-stressed rats in three discrete regions showed a significant increase $(p<0.05)$ when compared to other groups. Whereas chronic

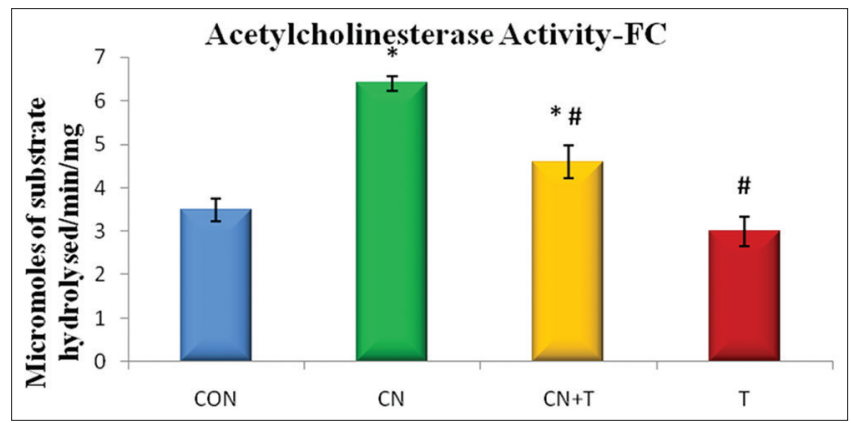

Fig. 2: Effect of Michelia champaca on acetylcholinesterase activity in frontal cortex. Values are expressed as mean \pm standard deviation, $n=6$. The symbols represent statistical significance: *,\# $\mathbf{p}<0.05$. *Compared with saline control. ${ }^{*}$ Compared with chronic noise stress

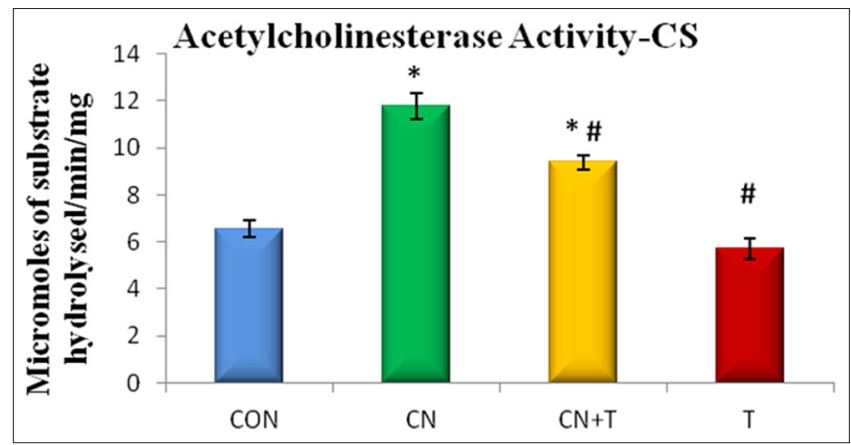

Fig. 3: Effect of Michelia champaca on acetylcholinesterase activity in corpus striatum. Values are expressed as mean \pm standard deviation, $n=6$. The symbols represent statistical significance: *,\# $\mathbf{p}<0.05$. *Compared with saline control. "Compared with chronic noise stress 


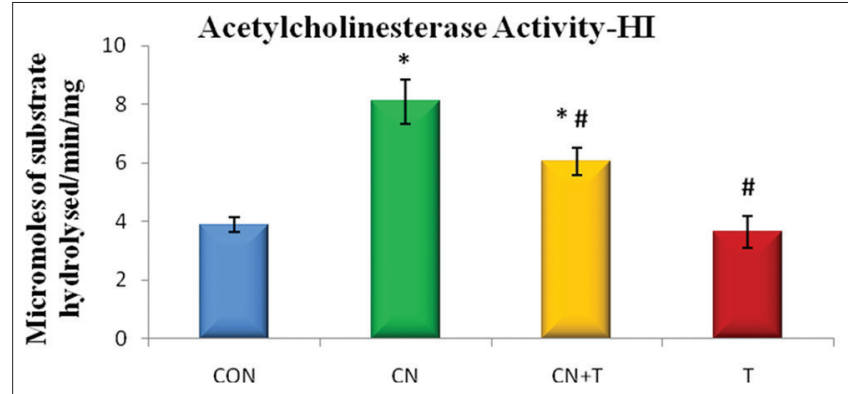

Fig. 4: Effect of Michelia champacaon acetylcholinesterase activity in hippocampus. Values are expressed as mean \pm standard deviation, $n=6$. The symbols represent statistical significance:

*,\#p $<0.05$. *Compared with saline control. "Compared with chronic noise stress

noise-stressed animal treated with M. champaca showed a significant decrease when compared to noise-stressed, control, and treated animals.

Effect of chronic noise stress on memory

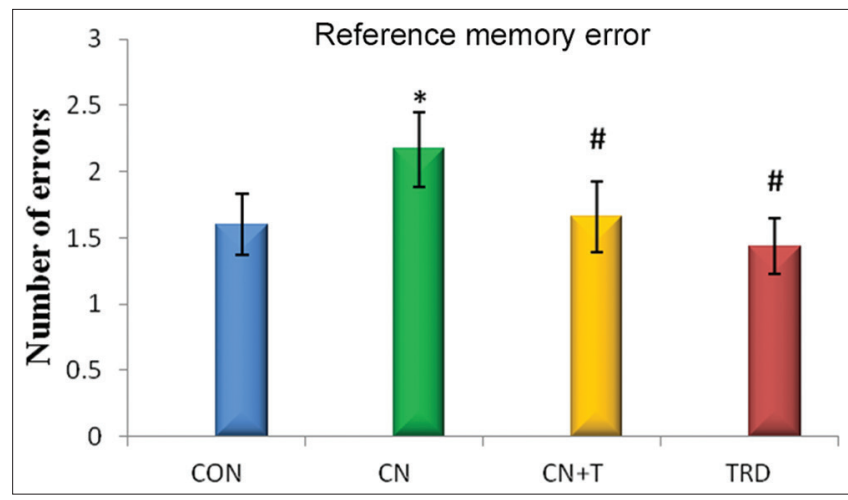

Fig. 5: Effect of Michelia champaca on reference memory error in chronic noise-stress-induced animals. Values are expressed as mean \pm standard deviation, $n=6$. The symbols represent statistical significance: ${ }^{*, \#} \mathbf{p}<0.05$. * Compared with saline control. ${ }^{*}$ Compared with chronic noise stress

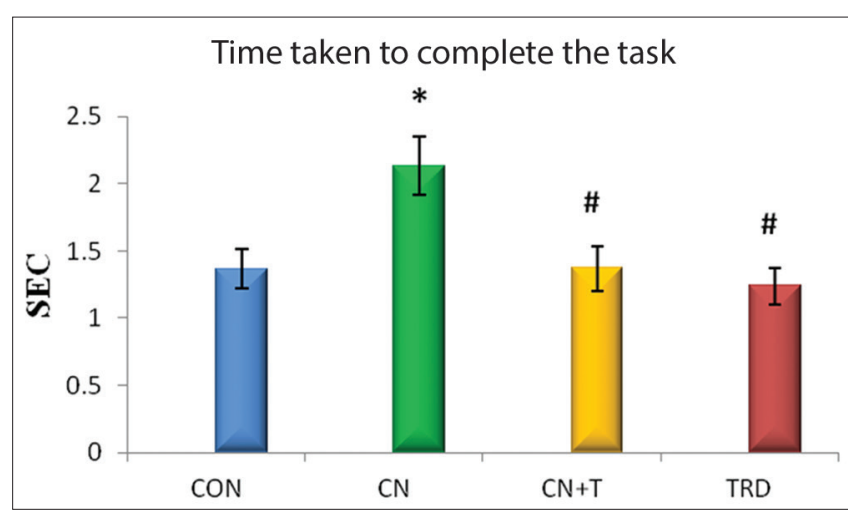

Fig. 6: Effect of Michelia champaca on working memory error in chronic noise-stress-induced animals. Values are expressed as mean \pm standard deviation, $n=6$. The symbols represent statistical significance: ${ }^{*, \#} \mathbf{p}<0.05$. ${ }^{*}$ Compared with saline control. ${ }^{\#}$ Compared with chronic noise stress

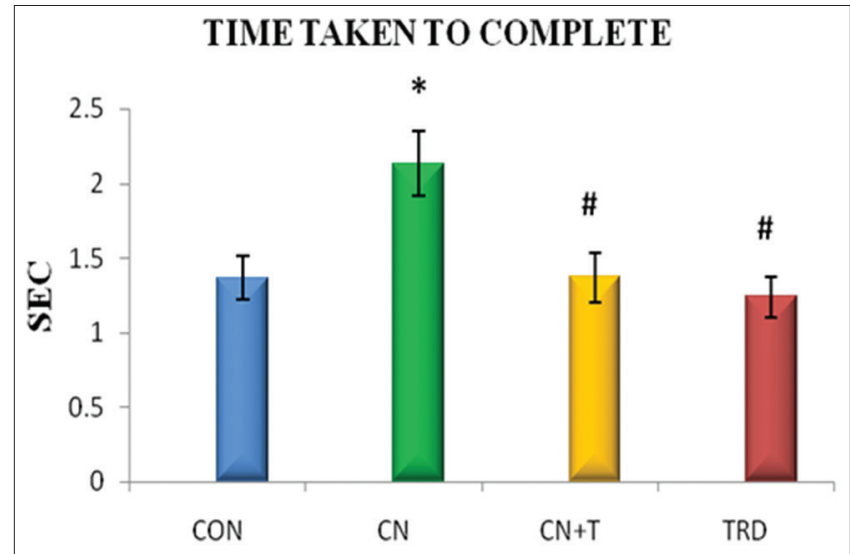

Fig. 7: Effect of Michelia champaca on time taken to complete the eight-arm radial maze in chronic noise-stress-induced animals.

Values are expressed as mean \pm standard deviation, $n=6$. The symbols represent statistical significance: ${ }^{*, \#} \mathbf{p}<0.05$. ${ }^{*}$ Compared with saline control. "Compared with chronic noise stress

\section{Reference and working memory error}

The data are summarized in (Figs. 5 and 6) with mean \pm SD. Based on Olton's definition, (1) Number of reference memory errors, i.e., each entry into a non-baited arm and (2) number of working memory errors, i.e., re-entries into already visited baited arms were noted down along with the (3) time taken to visit all the baited arms the scoring was done. Stress exposed animals show a significant increase in both reference and working memory error. Whereas in chronic noise stress animal treated with M. champaca can able to reduce the error when compared to control and control treated with M. champaca.

\section{Total time taken to complete the EAM}

The data are summarized in (Fig. 7) were expressed with mean \pm SD. The time taken by stress exposed animals to complete the EAM significantly increased. Whereas there was a significant decrease of time change was observed in noise animal treated with $M$. champaca. Control treated with $M$. champaca showed increased performance when compared to control animals in all the tasks, so M. champaca extract was found to be beneficial in memory enhancing.

\section{DISCUSSION}

Stress is an integral component of human life and is considered as any condition that leads to perturbation of the body's homeostasis [11] During extreme stress situations, the homeostatic mechanisms of the organism become deficient and the survival of the organism is thereby threatened. When stress is sustained over a long period, breakdown in adaptation occurs, and this leads to ill health and various pathological conditions [12].

Chronic stress has been linked to major physiological and psychological illness in humans. Stress has been suggested to be important in the development of hypertension, gastrointestinal disorders, immune suppression, reproductive dysfunction, and mental depression. Hormones appear to play a role in the development of some of these disorders. Cortisol regulation appears to be abnormal in some depressive illness [13]. Levels of plasma hormones have proved useful in determining the potential role of these hormones in stress-induced illness. In the present study, the corticosterone level was significantly increased in rats exposed to chronic noise stress when compared to other groups. Similar results were noticed by a Smookler and Buckley [14] in rats after 5 weeks exposure to noise, whereas increased level was prevented by the treatment of M. champaca in stressed rats 
treated with champaca. The marked increase observed in this study may be due to the effect of noise exposure, which leads to stimulation of hypothalamic-releasing hormones such as the stress peptide corticotropin-releasing hormone (CRH) [15].

It is evident that CRH initiates the HPA axis in response to stress and stimulates a release of adrenocorticotropic hormone [16] which, in turn, releases glucocorticoids from the adrenal cortex. This persistent increase in steroid level can be attributed to be due to the changes in the glucocorticoid receptor levels, which were associated with the altered glucocorticoid negative feedback sensitivity in rats [17]. Further, it appears that in noise-exposed pigs glucocorticoid feedback is exerted predominantly at the level of pituitary rather than at the $\mathrm{CRH}$ neuron level at hypothalamus. Even though the elevation of the steroid level after a number of stressors has already been reported [18], the sustained increase in corticosterone levels in prolonged noise exposure can be attributed to the accumulative effect of repeated noise exposure. Moreover, reports indicate that stress can be beneficial to some extent, and improper control of stress can lead to a variety of harmful diseases. It has also been reported that long-lasting activation of the HPA axis, especially long-term increase of cortisol cause immunosuppression, insulin resistance, cardiovascular diseases, catabolism, intestinal problems, etc. [19].

Acute and repeated stress has also been reported to have marked effects on the AChE activity of numerous brain nuclei. AChE is a key enzyme for the cholinergic transmission act on hydrolyzes the neurotransmitter acetylcholine. Ach to acetate and choline, thus play a central role in the nervous system.

The present study revealed that the effect of stress on AChE activity in the brain areas and memory function is dependent on the nature of stressors. There are also few reports, which suggest that the effect of stress depends on the kind and duration of stressors [20]. In the present study, we preferred the rats to obtain the profile of AChE activity in the three discrete regions of brain areas during stress and to correlate it with memory functions.

Das et al., 2000 [21] reported that acute- and chronic-predictable stress produced significant changes in whole brain AChE activity in mice, whereas only acute stress could improve learning and memory function. The same results were observed in the present study were chronic stress produces memory impairment.

Inhibition of AchE activity due to oxidative stress causes neurotoxicity in the brain [22]. The experimental study demonstrated that stressinduced changes in the central cholinergic system and reducing AchE activity [23]. Another study shows that the activity of AchE is reduced in conditions, oxidative stress, and this reduction is due to overproduction of $\mathrm{H}_{2} \mathrm{O}_{2}$ which oxidized many amino acid residues such as methionine, tryptophan, and cysteine in structure of protein, which can severely affect the enzyme functions [24]. In this work, the inhibition of AchE activity might be due to exposure to noise increase of free radical's production, causing disappointing the oxidant and antioxidant equilibrium in the brain, this lead to oxidative stress that reduced AchE function in the cholinergic system also alteration of AchE structure in the surface of the enzyme by the action of free radicals caused the reduction in enzyme activity.

In the present study, chronic noise stress significantly impaired memory of rats. Methanolic extract of $M$. champaca significantly reduced brain AChE activity in rats as compared to the stress group. This suggests that the memory enhancing the effect of $M$. champaca might be due to inhibition of AChE, leading to increase in brain levels of acetylcholine. Acetylcholine is considered to be one of the important neurotransmitter involved in the regulation of cognitive functions [25]. Cognitive dysfunction has been shown to be associated with impaired cholinergic transmission and the facilitation of central cholinergic transmission resulting in improved memory. Moreover, selective loss of cholinergic neurons in certain brain parts appeared to be a characteristic feature of senile dementia. The degeneration and dysfunction of cortical cholinergic neurons are closely associated with cognitive deficits of Alzheimer disease (AD) [26]. Thus, the drugs which enhance cholinergic function can be used for the treatment of dementia closely related to AD. The methanolic extract of $M$. champaca showed memory enhancing activity in rat probably by inhibiting brain AchE activity.

Stress induces structural and functional alterations in the central nervous system and particularly in hippocampus [27]. Hippocampal function is disturbed by the effect of chronic stress through such mechanisms as neuronal remodeling by dendritic retraction, suppression of synaptic activity and plasticity, [28] and altered neurogenesis [29]. In rats, chronic stress caused an impairment in the performance of a spatial memory task in EAM, Y-maze, and also a water maze [30,31]. Activitydependent changes in synaptic strength are considered mechanisms underlying learning and memory. There are not only the structural changes of neurons in cerebral cortex and hippocampus that affect activity-dependent changes in synaptic strength and alter learning and memory performance.

In random access memory test, the noise stress exposed animals showed a significant increase in the number of references and working memory errors and time taken to visit all the baited arms in the chronic noise stress animals when compare to other group animals [32]. Park et al. in his finding the restraint stress memory impairment developed only after 21 days. His report is supported by our chronic noise stress group findings. This might be due to the elevated corticosterone level which increases the corticosterone receptor in the hippocampus which leads to memory impairment [33]. Stress group treated with $M$. champaca caused reduction in the reference and working memory errors and time taken to visit all the baited arms was observed, retaining of memory in chronic noise stress treated with $M$. champaca might be due to the presence of memory enhancing compounds in champaca [7] which also prevents corticosterone elevation after noise stress. Hippocampus plays a critical role in learning and memory, and hippocampal damages cause cognitive impairment. In this study, memory impairment after noise stress exposure was due to hippocampal damage by increased generation of free radical and AChE activity in hippocampus which was correlated well with earlier reports where different stressors were used [34]. Hippocampal AChE activity was increased in 30 days noise-stress-exposed rats which were correlated well with Schloesser et al. [35]. Increase in the AChE activity leads to decrease in acetylcholine level in the synaptic cleft, results in decreased cholinergic activity, which in turn leads to memory impairment. Hornick et al. [36] were reported that selective central nervous system AChE inhibitor, improve cognitive performance. In this study, treatment with $M$. champaca normalized AChE activity might be due to cholinesterase enzyme inhibitor activity [37] which leads to memory enhancement action.

We have observed in this study after chronic noise stress exposure, animal showed a marked impairment of memory and increased corticosterone and AChE activity; these changes had been replaced to normal levels by administration of $M$. champaca and its active compounds present in it can able to prevented the memory impairment in noise-stressed rats treated with champaca.

Our study reveals that $M$. champaca possesses antistressor activity and reverses memory impairment which is induced by chronic noise stress in Wistar rats. The antioxidant, antistressor, anticholinesterase, and neuroprotective activities demonstrated by $M$. champaca playing a significant role in its positive effect on memory performance in rats exposed to chronic stress. Moreover, the finding that $M$. champaca decreases the levels of corticosterone a major indicator of stress response, further supports its use as a memory enhancer and in conditions associated with stress-related disorders.

\section{CONCLUSION}

Environmental noise is a common problem encountered in urban life regarded to evoke stress and risk factor in human health. In our 
present study, we observed that preventive action by $M$. champaca against memory impairment in a chronic noise exposure. It might be due to the antioxidant, AChE inhibitor, and anti-stressor properties of its compounds. M. champaca can be used as a remedy for stress induced memory loss. Further studies are warranted to elucidate exact mechanism of action of $M$. champaca and its active principle on neurons for their memory, promoting action in other animals, and also in human subjects, who are living in the noisy environment.

\section{REFERENCES}

1. Jayanthi LD, Ramamoorthy S. Regulation of monoamine transporters Influence of psychostimulants and therapeutic antidepressants. AAPS J 2005;7(3):E728-38.

2. Appleyard ME. Secreted acetylcholinesterase: Non-classical aspects of a classical enzyme. Trends Neurosci 1992;15(12):485-90.

3. Fatranská M, Kiss A, Oprsalová Z, Kvetnanský R. Acetylcholinesterase and choline acetyltransferase activity in some hypothalamic nucle under immobilization stress in rats. Endocrinol Exp 1989;23(1):3-10.

4. Yadav YC, Jain A, Deb L. A review: Neuropharmacological screening techniques for pharmaceuticals. Int J Pharm Pharm Sci 2010;2(2):10-4.

5. Wei1 LS, Wee W, Siong JY, Syamsumir DF. Characterization of antimicrobial, antioxidant, anticancer property and chemical composition of Michelia champaca seed and flower extracts. J Pharm Sci 2011;4(1):19-24.

6. Vimala R, Nagarajan S, Alam M, Susan T, Joy S. Anti-inflammatory and antipyretic activity of Michelia champaca Linn., (White variety), Ixora brachiata Roxb and Rhynchosia cana (Willd.) DC flower extract. Indian J Exp Biol 1997;35(12):1310-4.

7. Malathi S, Rajan R. Free radical scavenging activity, TLC, HPTLC and GCMS analysis of dry flower of Michelia champaca Linn. World J Pharm Res 2015;4:12

8. Singh DK, Verma R. Spectrophotometric determination of corticosteroids and its application in pharmaceutical formulation. Iran J Parmacol Therap 2008;7(1):61-5.

9. Ellman GL, Courtney KD, Andres V Jr, Feather-Stone RM. A new and rapid colorimetric determination of acetylcholinesterase activity. Biochem Pharmacol 1961;7:88-95.

10. Olton DS. Mazes, maps, and memory. Am Psychol 1979;34(7):583-96.

11. Zhu Q, Gu L, Wang Y, Jia L, Zhao Z, Peng S, et al. The role of alpha-1 and alpha-2 adrenoceptors in restraint stress-induced liver injury in mice. PLoS One 2014;9(3):e92125.

12. Panossian A, Wikman G, Kaur P, Asea A. Molecular chaperones as mediators of stress protective effect of plant adaptogens. Heat Shock Proteins and Whole Body Physiology. Vol. 5. Dordrecht: Springer; 2010. p. 351-64.

13. Kant GJ, Leu JR, Anderson SM, Mougey EH. Effects of chronic stress on plasma corticosterone, ACTH and prolactin. Physiol Behav 1987;40(6):775-9.

14. Smookler HH, Buckley JP. Effect of drugs on animals exposed to chronic environmental stress. Fed Proc 1970;29(6):1980-4

15. Nemeroff CB. The corticotropin-releasing factor (CRF) hypothesis of depression: New findings and new directions. Mol Psychiatry 1996;1(4):336-42.

16. Kemp CF, Woods RJ, Lowry PJ. The corticotrophin-releasing factorbinding protein: An act of several parts. Peptides 1998;19(6):1119-28.

17. Meaney MJ, Diorio J, Francis D, Widdowson J, LaPlante P, Caldji C, et al. Early environmental regulation of forebrain glucocorticoid receptor gene expression: Implications for adrenocortical responses to stress. Dev Neurosci 1996;18(1-2):49-72.

18. Kanitz E, Otten W, Tuchscherer M. Central and peripheral effects of repeated noise stress on hypothalamic-pituitary-adrenocortical axis in pigs. Livest Prod Sci 2005;94(3):213-24.

19. Spreng M. Possible health effects of noise induced cortisol increase. Noise Health 2000;2(7):59-64.
20. D’Aquila PS, Peana AT, Carboni V, Serra G. Exploratory behaviour and grooming after repeated restraint and chronic mild stress: Effect of desipramine. Eur J Pharmacol 2000;399(1):43-7.

21. Das A, Rai D, Dikshit M, Palit G, Nath C. Nature of stress: Differential effects on brain acetylcholinesterase activity and memory in rats. Life Sci 2005;77(18):2299-311.

22. Kazi AI, Oommen A. Monocrotophos induced oxidative damage associates with severe acetylcholinesterase inhibition in rat brain Neurotoxicology 2012;33(2):156-61.

23. Mineur YS, Obayemi A, Wigestrand MB, Fote GM, Calarco CA, $\mathrm{Li} \mathrm{AM}$, et al. Cholinergic signaling in the hippocampus regulates socia stress resilience and anxiety - And depression-like behavior. Proc Nat Acad Sci U S A 2013;110(9):3573-8.

24. Gralewicz S, Swiercz R, Lutz P, Wiaderna D, Wasowicz W. Effects of stress pretreatment on the dynamics of blood cholinesterase activity after exposure to an organophosphorus pesticide in the rat. Ann Agric Environ Med 2010;17(1):65-71.

25. Venero C, Tilling T, Hermans-Borgmeyer I, Schmidt R, Schachner M, Sandi C. Chronic stress induces opposite changes in the mRNA expression of the cell adhesion molecules NCAM and L1. Neuroscience 2002;115(4):1211-9.

26. Bartus RT, Dean RL $3^{\text {rd }}$, Beer B, Lippa AS. The cholinergic hypothesis of geriatric memory dysfunction. Science 1982;217(4558):408-14

27. Kulkarni PD, Ghaisas MM, Chivate ND, Poournima S. Memory enhancing activity of Cissampelos pariera in mice. Int J Pharm Pharm Sci 2011;3(2):206-11

28. Morris RG, Moser EI, Riedel G, Martin SJ, Sandin J, Day M, et al. Elements of a neurobiological theory of the hippocampus: The role of activity-dependent synaptic plasticity in memory. Philos Trans R Soc Lond B Biol Sci 2003;358(1432):773-86.

29. Astari AN, Sari DC, Aswin S, Suharmi S. The Effect of Administration Pegagan Ethanolic Extract on the Number of Hippocampal CA3 Pyramidal Neuron: Study on Rats (Rattus norvegicus) Post-stress Electricity with dose $300 \mathrm{mg} / \mathrm{kgBW}$ for 4 Weeks and 6 Weeks. Proceeding $23^{\text {rd }}$ European Students Conference $17^{\text {th }}-20^{\text {th }}$, Berlin, Germany.

30. Sari DC, Ar-Rochmah M. The Effect of Ethanol Extracts of Centella asiatica Leaf on the Retention of Spatial Memory in Rats (Sprague-dawley) after Chronic Electrical Stress. Buku Panduan dan Kumpulan Abstract Pertemuan Ilmiah Nasional Perhimpunan Ahli Anatomi Indonesia XIV Komisariat PAAI Denpasar; 2012.

31. Sari DC, Pratama RS, Aswin S, Suharmi S. The effect of Centella asiatica ethanolic extract's administration duration on spatial memory in rat (Rattus norvegicus) after electric - Stress induced. Jurnal kedokteran kesehatan mutiara medika UMY. Mutiara Medika J 2011;11(3):67-78.

32. Park HJ, Shim HS, Kim H, Kim KS, Lee H, Hahm DH, et al. Effects of glycyrrhizae radix on repeated restraint stress-induced neurochemical and behavioral responses. Korean J Physiol Pharmacol 2010;14(6):371-6.

33. Vreugdenhil E, de Kloet ER, Schaaf M, Datson NA. Genetic dissection of corticosterone receptor function in the rat hippocampus. Eur Neuropsychopharmacol 2001;11(6):423-30.

34. Silva-Gomez AB, Rojas D, Juarez I, Flores G. Decreased dendritic spine density on prefrontal cortical and hippocampal pyramidal neurons in postweaning social isolation rats. Brain Res 2003;983(1-2):128-36.

35. Schloesser RJ, Jimenez DV, Hardy NF, Paredes D, Catlow BJ, Manji HK. Atrophy of pyramidal neurons and increased stress-induced glutamate levels in CA3 following chronic suppression of adult neurogenesis. Brain Struct Funct 2014;219(3):1139-48.

36. Hornick A, Lieb A, Vo NP, Rollinger JM, Stuppner H, Prast H. The coumarin scopoletin potentiates acetylcholine release from synaptosomes, amplifies hippocampal long-term potentiation and ameliorates anticholinergic-And age-impaired memory. Neuroscience 2011;197:280-92.

37. Dhivya PS, Sobiya M, Selvamani P, Latha S. An approach to alzheimer's disease treatment with cholinesterase inhibitory activity from various plant species. Int J PharmTech Res 2014;6(5):1450-67. 